(Continued from page 836)

together with mitochondrial counts revealed a number of important modificetions occurring after feeding 3 -methyl-dimethylamino-zzobenzene. When '-methyl-dimethylamino-azobenzene wass substituted for the former dye, the changes were quite different in the early part of the experiment, but approached those observed with 3'-methyl-dimethylamino-azobenzene at later stages. Allard also described a number of electron-microscope observations made on pre-cancerous liver. Particularly interesting were some images suggestive of mitochondrial division and others indicating the appearance of small granules closely associated with ergastoplasmic membranes.

Some problems of mitochondrial reguletion were discussed by F. Lynen (Munich) and by J. D. Judah (Philadelphia). Lynen examined in detail the theory, proposed a number of years ago by himself and by M. Johnson, to account for the Pasteur effect in yeast. The mainspring of this theory is that glycolysis and oxidative phosphorylation compete for the limiting amounts of inorganic phosphate and adenosine diphosphate available in the cell. Thus, glycolysis is depressed aerobically and enhanced by anaerobiosis or by inhibition of aerobic phosphorylation. While this interpretation is supported by the results of phosphate analyses, it cannot explain the decreased aerobic utilization of glucose. To account for the latter phenomenon, Lynen has suggested that the adenosine triphosphate, formed aerobically in the mitochondria, may not be as readily available to the phosphokinases of the glycolytic system as the adenosine triphosphate formed in fermentation. Investigations aimed at verifying this possibility have confirmed the existence of an adenosine triphosphate shuttle between the particulate and the non-particulate phases of the cells, but have also revealed that phospho-fructokinase appears to bc inhibited preferentially to hexokinase in aerobiosis. At present, there is no satisfactory explanation for this finding. In the discussion which followed this interesting paper, the possible organizetion of the ground plasm was brought up for consideration by several speakers.

J. D. Judah described a series of recent investigations carried out in relation with the finding that severel anti-histamine drugs act as powerful protectors against experimental liver injury. It was observed that these drugs inhibit the swelling of isolated mitochondrie, as determined by a variety of conditions, and that they also inhibit the reversal of this phenomenon under the influence of aderosine triphosphate. In addition, anti-histamines were found to have no effect on respiration or on oxidative phosphorylation, but to inhibit the transfer of phosphate from adenosine triphosphate to phosphoprotein. When added to liver slices, previously incubated anaerobically, the drugs prevented the extrusion of water and restoration of the level of phosphoprotein which normally occur when oxygen is allowed to enter into the system. Judah put forward the hypothesis that the reversible changes in the water content of the mitochondria may be determined by changes in their content of phosphoproteins and that anti-histamines may prevent both types of changes by inhibiting a revorsible protein phosphokinase.

In the general discussion which concluded the meeting, the necessity for a closer co-operation between electron-microscopists, histochemists and biochemists was stressed. It was also pointed out that further progress in our knowledge of the orgenization of the cell will be greatly dependent on the development, in all three fields, of new methods of greater accuracy and increased power of resolution.

C. DE DCVE

\title{
THE PHYSICAL SOCIETY
}

$\mathrm{T}$ HE principal contents of the 1959 Year Book of the Physical Society (pp. vi +124 . London: Physical Society, 1959. 12s. 6d.), the fifth in the annual series, consists of the presidential address, entitled "Recent Trends in the Theory of the Ionosphere", which was delivered by J. A. Ratcliffe on May 21,1959 , following the annual general meeting of the Society, and the texts of the lectures and addresses given by the recipients of the various medals and prizes of the Society. Details are also given of the discourses delivered at the fifty-third Physical Society exhibition of scientific instruments and apparatus; the proceedings of the meetings of the Society during the period September 1958-June 1959 ; and the report of the Council of the Society for 1958. In addition, there are obituary notices of ten Fellows, including Sir Alfred Egerton, Prof. E. O. Lawrence, Prof. O. W. Richardson and F. Twyman.

In his presidential address, Mr. Ratcliffe gave a survey of recent ideas concerning the formation of the upper part of the ionosphere, known as the $F$ layer. From measurements of the atmospheric density at great heights and computations of the electron distributions, it would appear that the layer is produced by the absorption of a solar ionizing radiation in atomic oxygen, which is distributed through the atmosphere as it would be if mixing were nearly complete up to heights of about $400 \mathrm{~km}$. at least. When the radiation is incident normally, the absorp. tion coefficient of the radiation is such that electrons are produced most rapidly at a height of about $180 \mathrm{~km}$. Small alterations in the amount of mixing can produce marked changes in the electron distribution, and changes of this kind could be the cause of the observed winter anomaly in middle latitudes.

The forty-third Guthrie lecture, which was delivered by Sir Harrie Massey on April 8 at Oxford, was entitled "Collisions", and was confined to a discussion of a selected number of atomic collision phenomena including the elastic and inelastic collisions of electrons and of positrons with atoms, recombination and charge transfer processes in the upper atmosphere, and the dissociation of molecular ions by impact with gas atoms. The subject of the fifteenth Charles Vernon Boys P'rizo address given by Dr. D. West, of the United Kingdom 
Atomic Energy Authority, Harwell, was a description of the method of observing $\pi$-mesonic X-rays. The work discussed was carried out on the Liverpool synchrocyclotron during $1952-56$ and the main item of measuring equipment was a Hutchinson-Scarrott type kicksorter. It is most interesting, therefore, to find that the thirty-sixth Duddell Medal addresses, which follow Dr. West's article, were delivered by G. G. Scarrott on the application of computer techniques to nuclear physics instruments and by G. W. Hutchinson on 'memories' for nuclear physics.

In 1959 it was the turn of the Physical Society to arrange for the delivery of the Parsons Memorial Lecture, and Dr. C. R. Burch was invited to be the lecturer on October 22, 1959, at the Science Museum, London. He chose to speak about aspheric imaging systems and described the work in this field carried out by the University of Bristol's Optical Group during the past twenty years. Under Dr. Burch's inspiring influence, his devoted band of research workers, all of whom he proudly mentions by name and with affection, have made, many with their own hands, optical instruments of new and advanced design. Advanced testing methods, aspheric reflecting microscope design and manufacture, meniscus-
Schmidt camera design and manufacture, conecylinder and screw interferometers, and several applications particularly in the biological field of these instruments are all touched on in Dr. Burch's lecture.

The subject of the twentieth Thomas Young Oration, given by Prof. R. W. Ditchburn on November 12, 1959, was also of an optical nature. He dealt with problems of visual diserimination, and described various methods of recording eye-movements and the analysis of involuntary movements. Eye-movements, both voluntary and involuntary, are of importance in contrast discrimination, and from the study of the discrimination of hue, it appears that in some conditions, normal subjects give reports usually associated with defective colour vision. The question as to how far the results obtained on the living eye are related to theories of retinal action is discussed with reference to electro-physiological measurements of impulses in optic nerve fibre of animals.

The lectures and addresses were intended for a very wide audience, and are extremely well and clearly written. They deal with specialist subjects, but their contents do not require specialist knowledge to understand them. The Year Book is a worthy addition to all science libraries.

\section{THE COLONIAL DEVELOPMENT CORPORATION}

$\mathrm{T}$ $\mathrm{HE}$ annual report and statement of accounts of the Colonial Development Corporation for the year ended Decembor 31, 1959*, the first to appear over Sir Nutcombe Hume's signature as chairman, follows the general stylo of Lord Reith's recent reports. Eighty-oight continuing projects are reported, as against seventy-seven the previous year, including fifteen new projects totalling $\mathfrak{1 3}, 184,000$, of which four have been removed from the list, and $\$ 4,046,000$ further investment in existing projects was approved. Of the continuing projects, representing $£ 90$ million, of which $£ 60$ million has been spent, $45 \cdot 2$ per cent were concerned with utilities, $43 \cdot 1$ por cont with primary production and processing, and 11.7 per cent with commerco and industry, the corresponding figures for 1958 being $46 \cdot 9,40 \cdot 8$ and $12 \cdot 3$ per cent, respectivoly. No capital has yet been raised from outside sources, nor has any attempt beon mado to do so. Although the Corporation is now well established and its revenue is increasing, its present capital structure is unsuited to raising outside capital except with the Government's guarantee, but if the recommendations of the Sinclair Committee are adopted it should be much easier to devise a form of capital which would find purchasers among private investors without such a guaranteo. The Corporation, however, is nearing the end of the resources it can draw from the Government, and further capital may soon be needed if it is to go forward.

The report emphasizes the importance of the correct adjustment of the relation between the highly industrialized countrios and the under-developed countries of the world; and in these territories, for which the United Kingdom Government is responsible, the Corporation is in a unique position to assist

* Colonial Devclopment Corporation. Annual Report and Statement of Accounts for vear to 31.12.59. Pp. v+77. (London: H.M. stationery Otfice, 1960.) 5 s, net. in finding a solution to this problem. Even when money and technical aid are available, the capacity to put them to the best use is often lacking, and the Corporation has now built up an organization staffed by experienced people and designed for this very purpose. Their fitness for the task is shown both by the success now being achieved by the Corporation and by the fact that commercial interests, which have been hesitant to participate in risk ventures in territories the political and economic future of which was uncertain, have been reassured when the Corporation has beon ready to be associated with their investment.

To assist in securing the maximum use of the Corporation's experienced organization in Great Britain and abroed, the chairman is leading a mission of the general manager and all six regional controllers to Washington to discuss the possibilities of the Corporation working for the International Bank, the International Finance Corporation and the Development Loan Fund. To-day the Corporation is well equipped to make contact with and examine new projects anywhere in the present or former dependent territories, to negotiate or essist in negotiating the terms of investment, to arrange for the management of the project and to watch over its progress. Almost all its capital of $£ 130$ million is now committed, and the value of products by direct projects and associated companies in 1959 amounted to about $\mathfrak{1} 18$ million, much of which contributed to the export trade of the countries concorned. The stimulation of other development caused by the Corporation's example and initiative is more difficult to assess, but the report cites as examples now housing enterprises and ideas due to the Malaya Borneo Building Society and housing schemes in Africa and the Caribbean, and now standards for large-scale agricultural enterprises in Borneo set by Borneo 